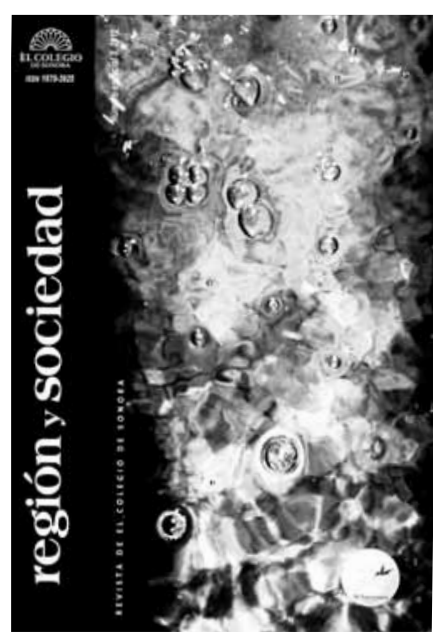

- Región y Sociedad

Número especial 3, 2012

El Colegio de Sonora, Hermosillo,

$328 \mathrm{pp}$.

\section{Agua disponible, agua inaccesible}

\author{
JOSÉ DE JESÚS HERNÁNDEZ LÓPEZ \\ Y LUIS GABRIEL TORRES GONZÁLEZ
}

Available Water, Inaccessible Water

José de Jesús HeRnÁndez LóPEZ

Centro de Investigaciones y Estudios Superiores en Antropología Social-Occidente,

Guadalajara, Jalisco, México jdejesus@ciesas.edu.mx

Luis Gabriel TorRes GonzÁlez

Centro de Investigaciones y Estudios Superiores en Antropología Social-Occidente,

Guadalajara, Jalisco, México Itorres@ciesas.edu.mx

Desacatos 46, septiembre-diciembre 2014, pp. 210-215

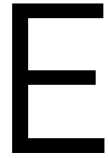

sta publicación es un número especial sobre el agua, dedicado a la memoria del geógrafo mexicano Ángel Bassols Batalla (19252012). La revista se integra por ocho artículos, una nota crítica y cuatro reseñas, y se caracteriza por la diversidad de enfoques disciplinarios. Jeffrey Bannister abre la sección de artículos con "Diluvios de grandeza: agua, territorio y poder en el río Mayo en el noroeste de México, 18801910”, y expone desde una perspectiva histórica el carácter estructural de la gestión del agua del Distrito de Riego 038 del Valle del Mayo, así como la forma en que la construcción de la infraestructura de riego ha impactado la vida social, el desarrollo económico y la gestión política. Bannister presenta una geografía fragmentada en la que los canales, las parcelas, los pueblos reubicados y los caminos han sustituido los bosques de saguaros, el matorral espinoso del desierto costero sonorense y la tranquila vida comunitaria en nombre del progreso y el desarrollo rural. No obstante la radical transformación, hay una constante entre el pasado y el presente en términos sociales. El autor aporta un enfoque valioso para comprender el quid problemático de quienes ejercen el 
poder en la gestión del agua y se propone seguir de cerca las circunstancias o momentos en que los administradores pierden el control del recurso. Además, relaciona esas circunstancias con las luchas en torno a la defensa de la tierra o de los derechos indígenas. Bannister examina cómo los ejercicios técnicos del tipo de la representación cartográfica son la punta de lanza del arte moderno de gobernar que busca establecer principios duraderos de visión y refundación del territorio, con una lógica diferente a la de los pobladores originarios.

Diana Luque, Angelina Martínez Yrízar, Alberto Búrquez, Eduwiges Gómez, Alejandro Nava y Moisés Rivera, en "Pueblos indígenas de Sonora: el agua ¿es de todos?”, exponen de manera descarnada los efectos no deseados de la política de desarrollo rural y la construcción de infraestructura para riego en lo que fueron territorios indígenas y zonas de alta biodiversidad y riqueza biocultural en todo el territorio sonorense. Enfocados en la ecología política y en un análisis transdisciplinario que privilegia la diversidad biocultural, los autores advierten las repercusiones más significativas del despojo de los territorios indígenas y sus recursos naturales. Los conflictos por el agua tienen mayor impacto en la supervivencia cotidiana de los nativos dado que incrementan la vulnerabilidad de las comunidades y aceleran la desorganización del complejo biocultural. Aparte de ratificar que la relación territorio-recursos naturales sigue siendo prioridad entre las demandas de los pueblos indígenas, los autores distinguen la "disponibilidad" de la "accesibilidad" al agua para dilucidar las claves o las posibilidades de apropiación del recurso hídrico — si efectivamente es de todos- y en otro sentido el despojo o exclusión de los grupos indígenas. Agregan además una diferencia a su enfoque de análisis: el "agua para la subsistencia tradicional" y el “agua para el desarrollo".

Los resultados de la investigación corroboran que los territorios indígenas siguen contribuyendo con casi $50 \%$ del agua y territorios de valor ambiental en medio de grandes variaciones. Entre los grupos étnicos sonorenses, sólo los mayos y los yaquis cuentan con una población significativa, mientras que en las otras etnias se observa una gran disminución poblacional. La Sonora pluricultural presentada por los autores muestra a cinco grupos étnicos muy disminuidos, como los cucapá, los seris, los pápagos, los pimas y los guarijíos. La ironía es que siguen viviendo en sus territorios ancestrales y aportando una gran cantidad de mano de obra y recursos naturales, pero son los que concentran los índices más bajos de desarrollo socioeconómico respecto del resto de la población sonorense. En contraparte, la visión de los grupos étnicos sobre la condición de los recursos naturales y el impacto del desarrollo capitalista hacia su territorio es muy crítica. Los ríos tienen poca agua o están casi secos todo el año. Los pobladores indígenas que se consideran aún dueños del agua sienten que cada vez tienen menos acceso real al recurso, puesto que éste es conducido en canales que van a parar a Hermosillo.

La subsistencia tradicional es una de las caras de la resistencia, pero apenas alcanza para amortiguar el impacto de la pobreza y detener el deterioro ambiental derivado del uso creciente de agroquímicos y contaminantes. La subsistencia es también la base para la preservación de la riqueza biocultural amenazada en mayor proporción por el cambio climático. El agua es, a fin de cuentas, otro indicador que confirma la inequidad étnica que prevalece en Sonora. Los autores llaman la atención sobre el valor estratégico del complejo biocultural en la construcción de una sociedad mundial pluricultural, no sólo porque en ese plano debe inscribirse la sociedad de Sonora, sino porque es además el único marco válido desde donde deben elaborarse las políticas públicas de desarrollo que se precien de ser ambientalmente sustentables.

Esther Padilla presenta el artículo "La construcción social de la escasez de agua: una perspectiva teórica anclada en la construcción territorial”. Parte 
del supuesto de que las relaciones de confrontación son el escenario ideal para conocer el problema de escasez hídrica, así como su representación en el territorio y sus inferencias como efecto de análisis en el desempeño de las relaciones o ejercicios de poder en torno a la gestión del líquido. Plantea un estudio de caso en el ejido San Miguel Horcasitas y su anexo, el pueblo de Los Ángeles en el mismo valle. Padilla precisa que es importante distinguir sequía de escasez: la primera se refiere a condiciones naturales y es de carácter climatológico; la segunda es una construcción social, política, interesada. Ambas suponen la insuficiencia de agua, pero la segunda es resultado del control de unos cuantos, manifiesta en una distribución inequitativa del agua disponible. Esto constituye un efecto de poder y es la condición que derivará en una confrontación, que se resolverá cuando uno de los bandos obtenga el control del territorio y convierta ciertos elementos del medio en "recursos controlables".

Mario Velázquez es el autor de "La construcción de espacios libres para la participación en las decisiones de política. El caso del acueducto Independencia en Sonora", artículo que tiene por eje la mencionada obra de trasvase que pretende evitar el colapso de la ciudad de Hermosillo. La cuestión es que las autoridades responsables priorizaron los usos urbanos, industriales, de ciertas empresas agrícolas y no atendieron los impactos que las obras provocarían en otros grupos y zonas, como Ciudad Obregón, desde donde se sitúa el autor. Velázquez muestra cómo a pesar de estar conformado por sectores provenientes de diferentes estratos sociales y sin un factor de identidad común y sólido, se constituyó el Movimiento Ciudadano por el Agua, cuyos participantes tomaron conciencia de los daños que podría provocar el trasvase en las zonas agrícolas y en la mancha urbana de Ciudad Obregón. El Movimiento utilizó ciertos "huecos" para difundir y enfocar su reclamo de certeza y claridad en la información respecto de los impactos de las obras. El gobierno argumentó que el problema de Sonora no era de escasez de agua sino de distribución ineficiente y buscó legitimarse como el repartidor justo entre la zona sur con más agua que la norte. En consecuencia, la intervención del gobierno como constructor de obras hidráulicas generó igualdad entre los habitantes de Sonora respecto del acceso al agua. Lo anterior da pie a que el autor reconozca los "espacios libres", de protesta e inconformidad, construidos desde los opositores a la obra porque no fueron tomados en cuenta. El autor también propone que desde el mismo Estado pueden construirse esos espacios libres, "pues resultan ser canales de negociación indispensables en una democracia" (p. 148) para tratar de resolver las demandas y romper con la idea de que cualquier mecanismo de solución implica un juego de suma cero. El costo puede ser el alargamiento de los tiempos para tomar decisiones, sin embargo el beneficio se encuentra en la reducción de incertidumbres ante los posibles efectos de un movimiento social, lo que incrementa además la legitimidad del gobierno.

Alejandro Salazar Adams, José Luis Moreno Vázquez y América Lutz Ley explican en "Agricultura y manejo sustentable del acuífero de la Costa de Hermosillo" que en esta zona existe un uso desproporcionado de agua en la agricultura comercial en relación con los beneficios que otorga la producción. Concentrados en un manejo sustentable, en la disminución de la sobreexplotación de los acuíferos y la contaminación con agua salina que viene aparejada, el objetivo de los autores es determinar la asignación óptima de cultivos en la Costa de Hermosillo mediante un modelo de programación lineal, así como proporcionar información para el establecimiento de políticas para el manejo sustentable. Ello permitiría a su vez destinar agua para el abasto urbano. En la realidad el uso no está regulado, es poco sustentable y se desconocen los acuíferos, considerados proveedores inagotables de agua. Existen normas, reglamentos, mecanismos, pero son inoperantes. Además hay otros factores a 
considerar, como el subsidio a la energía eléctrica que en cierto sentido fomenta "la gran extracción de agua y el dispendio del recurso, el uso de equipo ineficiente y cultivos no rentables" (p. 164).

Nicolás Pineda y Hugo Briseño titulan su artículo “¿Por qué son mejores los organismos de agua de Baja California que los de Sonora? Instituciones locales y desempeño de los organismos públicos", en el que enfatizan la importancia de las instituciones y la racionalidad como alternativa para reducir la incertidumbre y el desgaste, y optimizar el comportamiento de los sistemas de gestión del agua. Los autores comparan los organismos operadores del agua potable en ocho ciudades, cuatro de Baja California - Ensenada, Tecate, Tijuana, Mexicali- y cuatro de Sonora - Hermosillo, San Luis Río Colorado, Nogales y Ciudad Obregón-. Construyeron indicadores de los aspectos cruciales para garantizar el éxito de un organismo operador, tanto en el ámbito operativo como en el financiero, y encontraron que en Baja California hay mejores condiciones que en Sonora, por ejemplo, en el cobro de volumen de agua facturada. Una de las conclusiones es que ahí donde el servicio es responsabilidad del gobierno estatal las cosas funcionan mejor que cuando los responsables son los ayuntamientos municipales, siempre entrelazados en redes de relaciones clientelares, además de la rotación de puestos y la discontinuidad como sellos distintivos.

En "Gobierno y gestión de los servicios del agua en seis ciudades fronterizas" María Eugenia González y Socorro Arzaluz comparan tres ciudades de los estados de Coahuila y Tamaulipas y sus gemelas en el estado de Texas: Ciudad Acuña y Del Río, Nuevo Laredo y Laredo, Reynosa y McAllen. Analizan las prácticas de los organismos operadores del agua, con atención a la calidad del agua, entre otros aspectos. Estudian tendencias de crecimiento demográfico, la organización de la administración del agua en ambos lados de la frontera, las instituciones involucradas en la potabilización del agua, las leyes y las regulaciones relativas. Entre las diferencias encontradas está el papel protagónico del Consejo Ciudadano en la toma de decisiones, así como la facultad de las ciudades estadounidenses para emitir bonos en lugar de sólo depender de participaciones federales o de la recaudación, como sucede en México. Se contrasta la asignación de puestos por mecanismos tradicionales de los encabezados por profesionales. El servicio profesional de carrera se torna una necesidad y para ello es indispensable romper con redes clientelares. Otra cuestión de relevancia es la democratización de los organismos y de la información que generan o deberían generar. En ese proceso, como se mencionó, la participación ciudadana es fundamental.

El artículo de Jesús Armando Haro, Gerardina Nubes y J. Rubén Calderón Ortiz, "Riesgos sanitarios en calidad bacteriológica del agua. Una evaluación en diez estados de la República Mexicana”, examina cómo ante la escasez de agua el abasto es una preocupación de los organismos operadores, en contraste con los aspectos sanitarios o de la calidad del agua para consumo humano. Uno de los problemas que abre la puerta a la ineficiencia de los organismos operadores y al incumplimiento de la normatividad por parte de las empresas privadas que operan los servicios en algunos municipios, así como de la adulteración de agua que se vende en garrafones, es el vínculo directo entre los organismos y los gobiernos municipales, lo que dificulta su funcionamiento autónomo, profesional y desligado de criterios político-electorales. Hay datos preocupantes: México ocupa el segundo lugar mundial en consumo de agua embotellada -1690 litros por persona al año-, existen 6500 productoras de agua, de las cuales $84 \%$ son catalogadas como microempresas; 83\% del mercado es agua de garrafón; del total de purificadoras casi 2500 son "informales", es decir, operan sin controles sanitarios, y dominan 50\% del mercado nacional, sin contar a las clandestinas. La contaminación de acuíferos en el país es 
preocupante y el artículo dimensiona esa situación aunada a un manejo ineficiente que repercute en la salud de la población. Lo que debería ser una estrategia integral de gestión y vigilancia epidemiológica queda reducido a una conducción del sistema de información basado en un ineficiente monitoreo de la cloración.

La nota crítica que presentan Angelina Martínez Yrízar, Alberto Búrquez y Thierry Calmus, "Disyuntivas: impactos ambientales asociados a la construcción de presas", expone un contexto caracterizado por la construcción de grandes obras hidráulicas como símbolo de progreso, seguridad energética y abasto de agua. Los autores analizan los efectos ecológicos derivados de las presas vistas como herramientas de control y manejo del agua, y muestran que en este caso sí existe un juego de suma cero: cada embalse se construye a expensas de los servicios que proveen de manera gratuita los ecosistemas, los cuales tras su alteración tardarán en recuperarse o dejarán de funcionar. El problema no se limita a la zona del embalse, donde se pierde diversidad, pues la presión ejercida por la obra puede provocar sismos, además de que aguas abajo y hasta el océano se modificarán radicalmente por los procesos de erosión y deposición de sedimentos y arrastre de materia orgánica que contribuye a la vida acuática y marina. Se cuestiona la percepción dominante de las presas como fuentes de energía limpia. La nota concluye con una reflexión sobre los impactos sociales que provocará el proyecto "Los Pilares" entre los pobladores afectados. Las presas, símbolo del desarrollo social, o el Estado constructor de las mismas y generador de condiciones de vulnerabilidad, pobreza y marginación.

La revista culmina con cuatro reseñas. La primera sobre el libro Cultura hidráulica y simbolismo mesoamericano del agua en el México prehispánico, de Teresa Rojas, José Luis Martínez y Daniel Murillo, reseñado por Patricia Ávila, quien destaca el profundo conocimiento y respeto que las culturas prehispánicas tenían sobre la naturaleza y en particular sobre el agua. La segunda es acerca de Regadíos ancestrales en Iberoamérica. Técnicas y organización social del pequeño riego, volumen editado por Tomás Martínez Saldaña, Jacinta Palerm, Milka Castro y Luis Pereira. Blanca Jiménez destaca el valor del libro frente a la visión desarrollista dominante, en la que parece que los sistemas de riego ancestrales no tienen cabida, sin embargo encajan a la perfección como promotores del desarrollo local en zonas rurales de México. El tercer libro reseñado es Aventuras con el agua. La administración del agua de riego: historia y teoría, editado también por Jacinta Palerm y Tomás Martínez Saldaña. Luis Aboites advierte que en el volumen se encuentran temas como la relación entre obras hidráulicas y la formación del Estado, el debate sobre la pertinencia de la propuesta de Wittfogel y la discusión sobre la capacidad de los regantes para construir y administrar distritos de riego de diversos tamaños y grados de complejidad. La reseña de Valentina Campos sobre La decadencia del agua de la nación, de Luis Aboites, cierra esta sección. Campos enfatiza un asunto alrededor del cual todos los artículos de la revista bordan y que el autor ha señalado desde hace mucho: lo que caracterizaría al manejo del agua en el siglo xx es la existencia de un Estado débil para dominar, controlar e imponer las reglas para el uso racional y equitativo del agua en situaciones en las que diversos grupos sociales se resistieron.

El eje que articula todos los documentos es la relación entre la sociedad y los usos y la administración del agua. Este número de la revista Región y Sociedad abarca problemas relacionados tanto con la agricultura como con el abasto urbano, sobre todo de las ciudades, las pequeñas localidades son vistas por sus afectaciones. La industria no está visibilizada, lo que hace suponer que ha quedado subsumida dentro de la ciudad. A propósito, un asunto importante que le preocupó a Brigitte Boehm, tal vez una de las ausentes en las referencias bibliográficas de la 
obra, fue la estigmatización de la agricultura de pequeño riego o de los agricultores en pequeña escala como derrochadores del recurso debido a sus prácticas culturales de inundación, riego por gravedad o rodado, obligados a modernizar sus tecnologías. Además del desconocimiento del ciclo hidrológico del agua, esta situación sugería que quienes acusaban de excesivo el consumo de agua en la agricultura tradicional en muchas ocasiones estaban interesados en conducir el agua a las ciudades donde reside el mayor número de votantes, pero sin preocuparse por la eficientización de las obras de conducción de agua para el abasto urbano, por la potabilización y el tratamiento de las aguas residuales. De paso, ante la imposibilidad de los agricultores tradicionales de modernizarse, se proletarizarían — como lo señalan los primeros artículos de esta obra-, se convertirían en jornaleros y abrirían paso a las empresas agrícolas, extensivas, como el modelo estadounidense.

Varios artículos sugieren que más allá de resolver el problema del abasto urbano, simbolizado por proyectos hidráulicos de gran envergadura, impera una visión extractiva del agua, arraigada en una conceptualización antropocéntrica de la naturaleza como un recurso a consumir, lo cual resulta evidente en la estructura de la administración pública, en la inoperancia de las instancias responsables de la gestión del agua, en la ruptura de puentes entre sociedad y gobierno, en la indiferencia de los ciudadanos, todo lo cual parece conducirse por los cauces de la privatización de los servicios, que al final tampoco garantizan la calidad ostentada. A consecuencia de esa visión dominante de la naturaleza como fuente inagotable de recursos, que sólo precisa de ser conducida con obras hidráulicas y ser administrada de manera eficiente para su distribución y consumo racional, se ha dejado de atender la producción de agua. La respuesta, de acuerdo con los libros reseñados en la revista, no se encuentra en las tecnologías modernas sino en las prácticas culturales ancestrales, en lo que Luque y compañeros, citando a Boege, denominan "sistemas agrobiodiversos", algunos de los cuales se resisten a desaparecer en Sonora. D 